\title{
El derecho en la obra de Michel Foucault. Un desajuste entre prácticas y conceptualizaciones
}

\author{
Mauro Benente 1 \\ Universidad Nacional de José C. Paz - Argentina
}

Revista Derechos en Acción ISSN 2525-1678/ e-ISSN 2525-1686

Año 5/No 14, Verano 2019-2020 (21 diciembre a 20 marzo), 972-994

DOI: https://doi.org/10.24215/25251678e385

ORCID: https://orcid.org/000-0002-5111-5540

\section{Introducción}

Si bien los trabajos de Michel Foucault han tenido influencia en numerosas disciplinas, no abundan los estudios que tematicen sobre sus aportes al derecho. Durante quince años, las discusiones sobre la ley en la obra de Foucault giraron en apoyo o en respuesta a los desarrollos de Foucault and Law publicado por Alan Hunt y Gary Wickham en 1994. Con anterioridad, François Ewald había dedicado algunos párrafos al tratamiento del derecho en la obra de Foucault, con posterioridad se publicaron varios artículos, hasta que en 2009 apareció Foucault's Law de Ben Golder y Peter Fitzpatrick, quienes al año siguiente realizaron una compilación titulada Foucault and Law, con artículos ya publicados pero dispersos, y en el 2013 Golder compiló Re-reading Foucault: On Law, Power and Rights.

En este trabajo presentaré de la tesis de la expulsión enunciada por Hunt y Wickham, analizaré Foucault's Law, y finalmente enunciaré mi lectura crítica sobre el modo en que

\footnotetext{
Abogado, docente de la Facultad de Derecho de la UBA, de la Facultad de Derecho de la Universidad Nacional de José C. Paz, investigador CONICET.
} 
Foucault ha conceptualizado el derecho. Mi tesis indica que existe un desajuste entre las prácticas disciplinarias y la dimensión conceptual del derecho al momento de dar cuenta de ellas. Según creo, este desajuste se explica por: a- una errónea descripción de las prácticas, que lo llevó a una problemática conceptualización del derecho o; b- a pesar de realizar una prolija caracterización de las prácticas, mantuvo una deficiente conceptualización del derecho.

\section{La tesis de la expulsión}

Varios autores y distintas autoras han postulado que Foucault expuso una muy limitada conceptualización de la ley, pero quienes lo han precisado con mayor sustento han fueron Hunt y Wickham, tanto de modo individual (Hunt, 1992a, 1992b, Wickham, 2002, 2006), cuanto en su obra Foucault and Law. Allí postulan que Foucault "vincula la ley con la concepción negativa del poder de la cual se esfuerza por escapar" (Hunt, Wickham, 1994: 40). De este modo, adopta acríticamente la fórmula positivista que indica que la ley es una regla acompañada de una sanción (Hunt, Wickham, 1994: 41).

Para Foucault, lo distintivo de la modernidad es el funcionamiento disciplinario del poder, que a través del control sobre los movimientos, tiempos y comportamientos, busca tornar dóciles, obedientes y normales a los sujetos. En este escenario, las disciplinas y la ley constituyen "un proceso dual, pero opuesto" (Hunt, Wickham, 1994: 46): la ley mantiene un funcionamiento represivo y prohibitivo, y el accionar de los mecanismos disciplinarios, que es eminentemente productivo, "es asegurado, no por la ley sino por la normalización" (Hunt, Wickham, 1994: 49). El corazón te la tesis de la expulsión indica que la ley se encuentra asociada con un funcionamiento premoderno y represivo del poder, distinto y distante del accionar del poder disciplinario. Es por ello que Kennedy advierte que Foucault presenta una "discontinuidad radical entre el poder legal y el poder disciplinario" (1991: 356), y Hirst agrega que suele 
"contraponer la regulación legal y la regulación disciplinaria" (1986: 50) y por ello "las intervenciones legales devienen secundarias respecto a una masa de intervenciones normalizadoras" (1986: 50).

\section{Las tesis de la inclusión}

En diálogo con la tesis de la exclusión, una serie de trabajos subrayaron que Foucault no había ubicado a la ley en un papel secundario, sino que la situaba como un elemento fundamental del biopoder. En su temprana lectura, Ewald subrayó que "la formación de la sociedad disciplinaria no redujo de ningún modo el poder de la ley" (1986a: 138), sino que se fue transformando en norma, en un patrón de distinción entre normal y anormal. (1986b: 71, 1986c: 482). Por su lado, Beck subrayó que "la ley no fue excluida por las disciplinas: las dos son interdependientes" (1996: 493), y Tadros postuló que la ley actuaba como una bisagra que conectaba los dispositivos disciplinarios con las tecnologías gubernamentales (1998: 99).

Hunt y Wickham (1994, pp. 99-116) sospechaban que los desarrollos sobre la gubernamentalidad podrían reposicionar al derecho, pero el trabajo más refinado en este punto es Governed by Law?, de Nikolas Rose y Mariana Valverde. Su argumento central consiste en sustituir la preocupación por el derecho por el "complejo legal", que alude a un conjunto de "prácticas legales, instituciones legales, estatutos, códigos, autoridades, discursos, textos, normas y formas de juicio" (1998: 542). En lugar de focalizarse en la ley, resulta urgente investigar "el rol del razonamiento legal, las autoridades legales, los foros legales y las técnicas legales en las prácticas de gobierno de las sociedades modernas" (1998: 543). La perspectiva es interesante porque no reduce la problemática jurídica a un registro legal, pero presenta dos problemas: el concepto de "complejo legal" no precisa cuál es la relación de aquello que llamamos ley con las disciplinas y las prácticas gubernamentales; no se precisa de qué parte de la obra de Foucault podría derivarse el concepto. 
No queda claro si este concepto se construye con Foucault, o a pesar de Foucault.

\section{La otra ley de Foucault}

Gran parte de la labor de Golder y Fitzpatrick se construye en oposición a la tesis de la expulsión, y si bien admiten que en algunas intervenciones Foucault indicó que en sociedades disciplinarias la ley retrocedía, en otras mostró sus solapamientos con diferentes tecnologías de poder (2009: 56-59). Sin embargo, asumir que la ley es un rasgo del diagrama de poder moderno, implica preguntarse cómo se relaciona con las formas de poder, y las lecturas oscilan entre: a- subordinar la ley a los dispositivos disciplinarios y mostrar su lugar secundario; b- resituar su papel dentro las tecnologías de poder. Empero, estas perspectivas no advierten el doble plano de la ley, una ambivalencia entre "una ley subordinada y una ley superadora [surpassing], entre una ley que es confinada por la emergencia del poder disciplinario y el biopoder, y una ley que es ilimitada y siempre yendo más allá de sí misma y de aquello que quiere instrumentarla" (2009; 39). Estas dos dimensiones de la ley no implican una contradicción, sino una afirmación "enteramente consistente -y muy apropiada- sobre la ley" (2009: 39).

La ley no se puede limitar a una mera herramienta del poder soberano ni a un instrumento del poder disciplinario. Ella es "algo más" y posee dos dimensiones: "la ley determinada, y la ley responsiva [responsive] que está siempre inclinada más allá de sí misma, sensible a ser deshecha por la resistencia" (2009: 72). El carácter determinado se vincula con el diagrama de poder, mientras que la dimensión responsiva la relaciona con las resistencias, y si bien ambos aspectos tienen la misma importancia, aquí me ocuparé solamente del primero.

En la lectura que hacen Golder y Fitzpatrick, la ley se encuentra ligada a la formación de cuerpos de conocimiento y diferentes modalidades de poder, por lo que ella no es autónoma ni autosuficiente, sino que aparece "en términos relacionales" 
(2009: 60). De acuerdo con los autores, el objeto de estudio de Vigilar y Castigar es el análisis de "«las estructuras jurídicopolíticas de la sociedad", su "modelo jurídico-político»" (2009: 60-61). El entrecomillado que los autores incluyen, parece confirmar que el blanco de análisis de Foucault es la interconexión de la ley con otras variables -saber, poder, etc.-, pero esta inclusión no es más que un recorte de citas que desvirtúa las conceptualizaciones de Vigilar y castigar. $^{2}$

Golder y Fitzpatrick afirman que, para analizar las relaciones entre la ley, el poder, y los saberes, además de considerar que la ley no es autosuficiente, hay que remarcar que las disciplinas tampoco lo son: hay que demostrar "la relación necesaria que existe entre ley y poder" (2009: 61). Esto puede hacerse con dos ejemplos: 1- la vinculación entre las disciplinas y las ciencias del hombre; 2- la respuesta del poder disciplinario al sujeto indócil. Aludiré solamente al segundo, puesto que es el ámbito donde se podría leer con mayor nitidez la relación entre disciplinas y ley.

Los autores notan que indocilidad no puede ser completamente contenida por la norma: ella es indispensable, pero "hay

2 La primera de las citas, restituida de modo integral, indica que "la modalidad panóptica del poder -a nivel elemental, técnico, humildemente físico en que ella se sitúa- no está bajo [cursiva agregada] la inmediata dependencia y en la prolongación directa de las grandes estructuras jurídico-políticas de una sociedad" (Foucault, 1975: 223). No entiende cómo, de una frase en la cual se separa el panoptismo -el poder disciplinario- de la estructura jurídico-política, Golder y Fitzpatrick derivan que el objeto de estudio es la relación de dos planos explícitamente escindidos por Foucault.

Similares problemas existen en la segunda referencia. Foucault postula que "el siglo XVIII ha inventado las técnicas de la disciplina y del examen, un poco, sin dudas, como la Edad Media ha inventado la investigación judicial" (1975: 226). El procedimiento de investigación judicial representaba al "poder soberano arrogándose el derecho de establecer la verdad" (1975: 227), y fue una matriz fundamental en la constitución de las ciencias empíricas. Por su parte, el examen se transformó en la técnica de saber propia de las disciplinas, pero, y aquí viene la referencia que incluyen Golder y Fitzpatrick, la "investigación que ha dado lugar a las ciencias de la naturaleza se ha separado de su modelo político jurídico; el examen, en cambio, está siempre inserto en la tecnología disciplinaria" (Foucault, 1975: 228). No es posible explicar cómo, partiendo de este pasaje, se puede sostener el objeto de estudio de Vigilar y castigar es el "modelo jurídico-político" de la sociedad. 
un punto en el cual esas formaciones disciplinarias fracasan en hacer frente a la resistencia" (2009: 69-70). Las disciplinas identifican comportamientos anormales pero como carecen de mecanismos para aplicar sanciones, deben recurrir a otra modalidad: "en el indócil, límite de la disciplina, se posiciona la ley, una ley que debe estar dentro de la escena disciplinaria pero también mantenerse separada" (2009: 70). Aunque a primera vista el razonamiento parece atractivo, resultan problemáticos los pasajes de Vigilar y castigar que se incluyen para sustentar que la ley interviene como reacción a la indocilidad. Los autores recuerdan que, para Foucault, en el centro de los "sistemas disciplinarios, funciona un pequeño mecanismo penal. Beneficia con cierto privilegio de justicia, con sus propias leyes, sus delitos específicos, sus formas particulares de sanción, sus instancias de juicio" (Foucault, 1975: 180). Aunque aquí no queda claro cómo las disciplinas se valen del sistema legal, el problema es que, para Foucault, en el régimen disciplinario, el arte de castigar "se opone, pues, término a término una penalidad judicial" (Foucault, 1975: 185). La penalidad judicial no refiere a fenómenos observables sino a leyes que hay que memorizar; no diferencia individuos, sino que categoriza actos; no jerarquiza. sino que hace jugar la oposición binaria permitido/prohibido. Es así que, "los dispositivos disciplinarios han secretado una "penalidad de la norma", que es irreductible [cursiva agregada] a los principios y su funcionamiento a la penalidad tradicional de la ley" (Foucault, 1975: 185). Golder y Fitzpatrick sostienen que, en los casos de indocilidad, las disciplinas se apoyan en la ley, pero una lectura prolija de Vigilar y castigar muestra una nítida diferencia entre el castigo legal, y las sanciones disciplinarias. Los autores pretenden sustentar su lectura y, citando a Foucault, recuerdan que las disciplinas "en apariencia, no constituyen más que un infra-derecho" (1975: 224). Sin embargo, no agregan aquello que incluye a continuación: a primera vista las disciplinas parecen prolongar a nivel particular las formas del derecho, pero más que un infra-derecho "hay que ver en las disciplinas una especie de contra-derecho [itálicas agregadas]" (1975: 224). 
Golder y Fitzpatrick afirman que al describir cómo frente a la indocilidad la norma recurre a lo jurídico, "Foucault está demostrando la dependencia de las disciplinas respecto de la ley" (2009: 70) y es "en el límite de la indocilidad generativa que la cientificidad de las normas cede paso a la aplicación jurídica de la ley" (2009: 70). Empero, es problemático focalizarse en la indocilidad sin tematizar sobre aquello que en $E l$ poder psiquiátrico Foucault había calificado como "residuos". Allí postulaba que las instituciones disciplinarias generaban en su seno individuos que no se ajustaban a los parámetros de normalidad, que "escapaban a la vigilancia" (2003: 55). Generaban casos parecidos a la indocilidad, pero, a diferencia de lo que plantean Golder y Fitzpatrick, a quienes no se ajustaran al parámetro de normalidad no les esperaba la ley sino otro dispositivo disciplinario (Foucault, 2003: 56). Asimismo, resulta extraña la falta de análisis del resumen de Los anormales, donde se expone la situación del niño indócil, que ya no es correlato de la ley:

la aparición del incorregible es contemporánea a la puesta en práctica de las técnicas de disciplina [...] Los nuevos procedimientos de encauzamiento del cuerpo, del comportamiento y de las aptitudes inauguran el problema de quienes escapan a esta normatividad que ya no es la soberanía de la ley [itálicas agregadas] (2001a: 1692).

Los incorregibles escapan a una normatividad que no es la ley, que a su vez es asociada a la prohibición: "la "prohibición" constituía la medida judicial mediante la cual un individuo era, al menos parcialmente, descalificado como sujeto de derecho" (2001a: 1692). Reduciendo el marco jurídico a un dispositivo negativo, y mostrando que no son las leyes sino los métodos positivos del enderezamiento los que actuarán sobre el indócil, Foucault subraya que "ese marco, jurídico y negativo, va a ser en parte ocupado y en parte reemplazado por un conjunto de técnicas y procedimientos con los que se emprenderá encauzar a aquellos que se resisten al encauzamiento y corregir a los incorregibles [itálicas agregadas]" (2001a: 1692). Mientras el Foucault que presentan Golder y Fitzpatrick muestra que la 
ley se pone en funcionamiento ante la presencia de individuos indóciles, el Foucault que se lee en Los anormales enfatiza que para responder a la indocilidad la ley fue ocupada y reemplazada por las disciplinas.

Golder y Fitzpatrick observan una correlación entre la ley y las disciplinas, pero para sustentarlo construyen un relato imaginario de las conceptualizaciones foucaulteanas. Sin embargo, suponiendo que estas dificultades puedan salvarse, los autores no logran desterrar la tesis de la expulsión: 1. Afirmar que las disciplinas necesitan de las leyes, no implica que tengan un rol predominante en el diagrama de poder. Aunque las disciplinas necesiten de las leyes, ello no las quita de un segundo plano; 2. Suponiendo la existencia de una relación entre disciplinas y leyes, no necesariamente desterramos la hipótesis del funcionamiento prohibitivo estas últimas, algo que puede ilustrarse realizando un paralelismo con el accionar de la familia. En $E l$ poder psiquiátrico, Foucault indica que la familia fijaba a los individuos a las instituciones disciplinarias -obligando a los niños a ir a la escuela, a los jóvenes a realizar el servicio militar-, y era una bisagra entre diferentes instituciones, porque permitía el pasaje de un sistema disciplinario a otro -enviaba al indócil escolar al reformatorio-. La familia cumplía un papel importante en las sociedades disciplinarias, pero no por ello funcionaba de modo disciplinario, sino que actuaba de acuerdo con un modelo soberano de poder: manteniendo un esquema de individualización del poder en la cima -en el padre-, y sin situar la vigilancia como constitutiva de su organización (1999: 81-84). Que una institución, sea la ley o la familia, se vincule con las disciplinas no implica que funcione con racionalidades disciplinarias.

Creo que una lectura atenta del trabajo de Golder y Fitzpatrick muestra que el costo que hay que pagar para afirmar que existe una íntima relación entre la ley y disciplinas no es otro que distorsionar severamente las conceptualizaciones foucaulteanas. Además, incluso asumiendo la relación entre disciplinas y derecho, no se desecha la tesis de la expulsión: en ningún momento se refuta su carácter prohibitivo y secundario. De 
todas maneras, esto no implica que la tesis de la exclusión sea la lectura correcta de la obra de Foucault.

\section{El desajuste entre prácticas y conceptualizaciones del derecho}

En línea con la tesis de la expulsión, creo que es posible construir un piso mínimo sobre la (no) relación entre disciplinas y derecho: Foucault establece una separación entre el poder disciplinario y el sistema legal, y sitúa a éste a un segundo plano. Para la tesis de la expulsión esto es así porque la ley solo prohíbe y reprime, pero este diagnóstico es parcialmente correcto ya que los problemas que ha tenido Foucault se explican por no haber ajustado su conceptualización de la ley a las prácticas analizadas: a- sea porque no describió correctamente las prácticas de poder, y no advirtió que estaban articuladas por el derecho; b- sea porque estaba describiendo prácticas de poder en las cuales las leyes tenían un rol constitutivo, pero a nivel conceptual las redujo a simples mecanismos de prohibición y/o a derechos liberales despojados de toda tecnología de poder.

Foucault distinguió diversas formas de poder -soberano, disciplinas, biopolítica- porque advirtió diferentes modalidades en su funcionamiento: ante las mutaciones de las prácticas modificaba las conceptualizaciones. Sin embargo, respecto de la ley, la conceptualización ha sido genérica, sin adjetivaciones, como si el derecho no se transformara junto con las modificaciones en las prácticas de poder. En este sentido, a diferencia de la tesis de la expulsión -que postula que Foucault quedó preso de una concepción soberana del derecho-, entiendo que el problema es más grave: en sus conceptualizaciones nunca calificó al derecho, y lo presentó como una variable constante en medio de discontinuidades de las prácticas de poder.

Para ordenar mis argumentos presentaré: a- la escisión entre, por un lado el contractualismo y el liberalismo, y por otro las disciplinas, y la ubicación del derecho en la orilla liberal; b- la reducción de las leyes a meras herramientas de prohibición 
y por ello distantes de las disciplinas. Para mostrar el desajuste entre prácticas disciplinarias y conceptualizaciones del derecho me detendré en ciertos arquetipos de las disciplinas, y sostendré que estamos frente a mecanismos delineados por dispositivos legales, algo que Foucault no logró advertir por una deficiente descripción de las prácticas; y en los casos en que la descripción fue correcta, conceptualizó erróneamente el papel de ley. Foucault ha fallado en su conceptualización, pero realizando las correcciones necesarias es posible sostener que las leyes son, o pueden ser, disciplinarias. ${ }^{3}$

\section{La separación entre poder disciplinario y derecho}

La forma que adquiere el diagrama de poder en las sociedades que emergen en los siglos XVIII y XIX supone un disciplinamiento del cuerpo individual y una regulación de las poblaciones. Las disciplinas despliegan una vigilancia de los cuerpos, del espacio que ocupan, del modo en que utilizan el tiempo, del desarrollo y coordinación de sus actividades, siendo el resultado de esta operatoria, un cuerpo dócil y normalizado. Si bien en ningún momento lo profundiza, reiteradamente Foucault separa el funcionamiento de las disciplinas de las leyes, e incluso postula que las prácticas médicas son más importantes que las legales. Las disciplinas

no operan a través de la ley, sino en sus intersticios. La ley no tiene potestad en la tecnología de sujeción de los cuerpos. Esa tarea recae en un sistema de "no-derecho" que se sirve de la norma como patrón de ordenamiento, control y elaboración de la población (Castro Orellana, 2004: 121).

Esta disociación entre disciplinas y ley se enuncia en distintos trabajos, incluso en los estudios sobre la prisión, en principio cercana a las instituciones legales. Así, Foucault proponía "analizar los métodos punitivos no como simples consecuencias de las

\footnotetext{
3 En anteriores apartados aludí a la biopolítica y a la gubernamentalidad, pero por razones de espacio me limitaré a los problemas en el abordaje de las disciplinas.
} 
reglas de derecho" (1975: 28), teniendo en cuenta que el encierro "interviene menos en nombre de la ley que en nombre del orden y de la regularidad" (2001b: 1332). Los mecanismos de poder

están ubicados bajo el signo visible de la ley. Pero, de hecho, los mecanismos más numerosos, más eficaces y más incisivos, funcionan en los intersticios de las leyes, según modalidades heterogéneas al derecho y en función de objetivos que no son del respeto de la legalidad, sino la regularidad y el orden" (2001c, pp. 274-275).

La normalización es irreductible a la ley, y por ello las figuras centrales en la constitución del orden no son los y las juristas sino los médicos y las médicas, quienes inventaron "una sociedad de la norma y no de la ley. Lo que rige la sociedad, no son los códigos, sino la distinción permanente entre lo normal y lo anormal, la empresa perpetua de restituir el sistema de normalidad" (2001d: 50).

De acuerdo con la tesis de la expulsión, la escisión entre leyes y disciplina se funda en la reducción de la ley a un simple mecanismo represivo. Sin embargo, en el plano conceptual, Foucault no solamente limitó el derecho a prohibiciones, sino que, simultáneamente, lo redujo a los derechos liberales. Sea que tengamos a las leyes como herramientas de prohibición, o como derechos de libertad e igualdad, se comprende perfectamente su separación del poder disciplinario. Sin embargo, esta disociación se sustenta en una mirada muy estrecha de la ley: en un caso desligada de toda racionalidad de poder, en el otro vinculado a una racionalidad meramente prohibitiva y represiva.

\section{VI.a. Liberalismo, contractualismo y disciplinas}

Una parte de la separación entre el derecho y las disciplinas debe inscribirse en la escisión entre, de un lado el liberalismo y el contractualismo, y por otro el poder disciplinario. Foucault recuerda que los historiadores atribuyen el sueño de una sociedad perfecta a los filósofos y los juristas del siglo XVIII, pero mientras ellos "buscaban en el pacto un modelo primitivo para 
la construcción o la reconstrucción del cuerpo social, [...] los técnicos de la disciplina elaboraron los procedimientos para la coerción individual" (1975: 171). Quienes diseñaron la máquina disciplinaria no fueron los juristas, y sus engranajes no estaban constituidos por leyes.

Las orillas del contractualismo y el liberalismo, y las de las disciplinas, no están completamente desconectadas, sino que por momentos el liberalismo se presenta encubriendo el funcionamiento del poder disciplinario: para que el

liberalismo burgués haya sido posible al nivel de las instituciones, ha sido necesario, a nivel de lo que denomino los micropoderes, un recubrimiento mucho más ceñido de los individuos, ha sido necesario organizar el cuadriculado de los cuerpos y de los comportamientos. La disciplina es el reverso de la democracia (2001e: 1590).

En el marco de esta separación entre contractualismo/liberalismo y poder disciplinario, Foucault ubicó al derecho del lado del liberalismo. La burguesía instaló un marco jurídico codificado, formalmente igualitario, y un sistema de gobierno representativo. Sin embargo, el "sistema de derechos en principio igualitarios estaba sostenida por esos mecanismos menudos, cotidianos, y físicos, por todos esos sistemas de micro-poder esencialmente desigualitarios y disimétricos que constituyen las disciplinas" (1975: 223). De esta manera, las "disciplinas reales y corporales han constituido el subsuelo de las libertades formales y jurídicas" (1975: 223). Como ya he mencionado, las disciplinas son una especie de "contra-derecho", y han sido "la contrapartida política de las normas jurídicas según las cuales se redistribuía el poder" (1975: 225).

$\mathrm{Al}$ sostener que las disciplinas representan un "contra- derecho", Foucault reduce ese derecho a los derechos liberales. Si el diagrama de poder disciplinario funciona a contrapelo del liberalismo, se entiende por qué el derecho ha quedado en un segundo plano. Este es uno de los motivos del repliegue de la ley. El otro es su reducción a una mera herramienta de prohibición 


\section{VI.b. La ley y el derecho como prohibición}

En los trabajos de la década de 1960 y los primeros años de 1970, Foucault mantenía una concepción represiva del funcionamiento del poder (1984, 2001f, 2001g: 445, 2001h: 986, 2001i: 1363-1364, 2001j: 1047, 2001k: 1072, 20011: 12981299, 2001m: 1286). Si bien en La sociedad punitiva, La verdad y las formas jurídicas, y fundamentalmente en $E l$ poder psiquiátrico, ya había delineado los trazos más importantes del funcionamiento del poder disciplinario, recién en Los anormales, Vigilar y castigar, "Hay que defender la sociedad", e Historia de la sexualidad I, se desprendió de la concepción negativa, represiva y prohibitiva del poder, y lo conceptualizó en términos positivos y productivos. Lo notable es que en estos trabajos es donde se lee con mayor nitidez una ley reducida a una herramienta de prohibición y de represión. ${ }^{4}$

A la luz de las prácticas de poder que describía, Foucault fue modulando su conceptualización, y como resultado de ese ajuste, aquello que a inicios de la década de 1970 concebía en términos represivos y prohibitivos, hacia mediados del decenio fue definido bajo una dimensión productiva. Empero, ese cuidadoso ajuste entre prácticas y conceptualizaciones se diluye en el ámbito del derecho.

En Vigilar y castigar, gran parte de la mirada represiva sobre el derecho se vislumbra en las referencias al derecho penal, y en su comparación con el castigo disciplinario. Mientras los castigos judiciales son la multa y el calabozo, el castigo disciplinario es "isomorfo a la obligación misma; ella es menos la venganza de la ley ultrajada que su repetición, su instancia redoblada [...] Castigar es ejercitar" (1975: 182). De acuerdo con Foucault "el arte de castigar, en el régimen del poder disciplinario, no apunta ni a la expiación, ni tampoco exactamente a la represión" (1975: 185). Refiere a reglas a seguir, y a partir de

4 La ley reducida a una herramienta represiva también se encuentra en Foucault (2001p: 567, 2001q: 1002, 1005, 1017-18, 2001r: 305). 
éstas, cualifica, compara y establece jerarquías, racionalidad que es incompatible con el juego de lo prohibido y permitido: "los dispositivos disciplinarios han secretado una "penalidad de la norma", que es irreductible a los principios y su funcionamiento a la penalidad tradicional de la ley" (1975: 185). Una de las razones por las cuales la penalidad de la norma es irreductible a la de la ley, es porque ésta se observa solamente en una dimensión negativa: únicamente prohíbe. Esto puede tener validez para el derecho penal, pero Foucault lo extiende a todo el sistema legal: erróneamente generaliza que "el pensamiento jurídico distingue lo lícito y lo ilícito [itálicas agregadas]” (2001n: 374).

Foucault sostenía que para estudiar las relaciones de poder había que abandonar la representación jurídica, que posee una mirada muy escueta sobre el poder porque: a- supone un funcionamiento limitado y monótono en estrategias y tácticas; b- indica que se encuentra únicamente en condiciones de impedir, e incapaz de producir comportamientos; c- por último, y aquí aparece la reducción de la ley a una mera prohibición, sería "un poder cuyo modelo sería esencialmente jurídico, centrado en el sólo enunciado de la ley y el sólo funcionamiento de lo probibido [itálicas agregadas]" (1976: 113). Cuando se define al poder a la luz de "la represión, se brinda una concepción puramente jurídica de ese mismo poder, se identifica al poder con una ley que dice no; que tendría sobre todo el poder de probibir [itálicas agregadas]" (20010: 148). Hay que abandonar esta representación jurídica y avanzar hacia una concepción del poder "que sustituya el privilegio de la ley por el punto de vista del objetivo, al privilegio de lo probibido por el punto de vista de la eficacia táctica [...] El modelo estratégico, más que el modelo del derecho [itálicas agregadas]" (1976: 135). ${ }^{5}$

\footnotetext{
5 Para estudiar las relaciones de poder se acudía a las formas jurídicas, "que regían lo que estaba permitido y lo que estaba prohibido" (2001n: 378). Sin embargo, el derecho "que divide lo permitido y lo prohibido, de hecho, no es más que un instrumento de poder, en definitiva, bastante inadecuado y bastante irreal y abstracto [...] las relaciones de poder son mucho más complejas, y es justamente todo esto extrajurídico, todas esas coacciones
} 
Esta apelación al modelo estratégico en perjuicio del modelo del derecho no es caprichosa, sino que se ajusta a las modalidades del diagrama de poder, puesto que una de las consecuencias del despliegue del biopoder es "la importancia creciente tomada por la norma en detrimento del sistema jurídico de la ley" (1976: 189). ¿Por qué este retroceso de la ley y la emergencia de la norma? Porque "la ley no puede no estar armada, y su arma, por excelencia, es la muerte; a aquellos que la transgreden, responde, a menos a título de último recurso, por esta amenaza absoluta. La ley se refiere siempre a la espada [itálicas agregadas]" (1976: 189).

La separación entre el derecho y las disciplinas se explica porque el derecho fue conceptualizado en términos liberales y entonces ajeno a las prácticas de poder; o vinculado a prácticas represivas, y por ello ajenas a la racionalidad disciplinaria. En lo que sigue me interesa revisar algunos problemas en la relación entre prácticas y conceptualizaciones del derecho.

\section{Derecho y disciplinas}

Uno de los aportes más originales de Foucault fue descartar la construcción de una teoría del poder, y en su lugar proyectar una analítica, una economía de las relaciones de poder. Es por ello que gran parte de sus conceptualizaciones eran inmanentes a las prácticas que estaba analizando. Lejos de desplegar construcciones teóricas sobre las prácticas, propuso rastrear la particularidad de éstas para luego derivar las conceptualizaciones. De hecho, algunas de sus herramientas conceptuales eran tomadas de los materiales de archivo que abordaba: es el caso de cuerpo dócil que se lee en un texto de Pinel (1801: 192); de los medios del buen encauzamiento que están en El arte militar para la infantería de Johann von Jacobi Walhausen; de panoptismo, extraído de los textos de Bentham, entre otros. Estas 
conceptualizaciones, restituidas de las prácticas, se constituían, en un movimiento casi circular, en una precisa grilla para analizarlas.

En el tratamiento del derecho, Foucault no ajustó su conceptualización al funcionamiento práctico. Ha desatendido el plano jurídico en las prácticas disciplinarias, no logró advertir su papel constitutivo en las instituciones disciplinarias que se encontraba analizando y, en el plano conceptual, ha dejado al derecho en un lugar secundario del diagrama general de poder.

\section{VII.a. La ley y las disciplinas}

Foucault sostuvo que la emergencia del encierro como tecnología de castigo se había producido por fuera del penalismo ilustrado, y tenía su origen en prácticas no estatales en Inglaterra, y a partir de las lettres-de-cachet en Francia. Teniendo en cuenta esta descripción, la penalidad que busca corregir a través del encierro "no aparece, a decir verdad, en el universo del derecho" (2001s: 1471). Es así que el encierro "interviene menos en nombre de la ley que en nombre del orden y de la regularidad" (2001b: 1332). Conceptualmente, Foucault mostraba que el encierro disciplinario tenía escasa vinculación con la ley, pero las prácticas mostraban que los encierros se instituían por las lettres-de-cachet que, si bien no eran leyes, eran algo muy parecido: decretos reales. No eran normas generales, eran lo opuesto a las lettres patentes, pero se parecían a aquello que, frente a la inexistencia de parlamentos, en términos amplios podríamos denominar legislación.

En Elpoderpsiquiátrico, luego de describir el funcionamiento de las disciplinas en instituciones religiosas, Foucault narra que durante el siglo XVIII proliferaron prácticas disciplinarias laicas, una de las cuales tenía como blanco los trabajadores y las trabajadoras industriales. Para disciplinarlos y disciplinarlas se instauró la cartilla laboral, en la que se consignaba quiénes habían sido los antiguos empleadores, las razones de salida de anteriores trabajos, y otros antecedentes. Ahora bien, y aunque 
Foucault no lo haya notado, durante los siglos XVIII y XIX en Francia, la regulación de la cartilla fue instaurada por numerosas disposiciones legislativas. Las primeras reglamentaciones datan de las lettres patentes del 2 de enero de 1749, luego se regula con el artículo 40 del edicto de Turgot de abril de 1776 y, años más tarde por las lettres patentes del 12 de septiembre de 1781. Finalmente, el artículo 12 de la ley sobre policía del trabajo del 12 de abril de 1803 incluyó una regulación de la cartilla obrera, que también aparece en la ley del 18 de marzo de 1806 y en el decreto del 11 de junio de 1809. En todos los casos, en mayor o en menor medida, se obligaba a los empleadores a requerir la cartilla antes de contratar un obrero u obrera (Le Crom, 2003: 91-93). Pero no eran únicamente las normas laborales las que obligaban al uso de la cartilla, sino que el artículo 217 del código penal disponía que, si un obrero no contaba con ella, se lo consideraba vagabundo, podía ser arrestado, y condenado a prisión (Le Crom, 2003: 93). El propio Foucault cita las cartillas, pero como no profundizó la descripción y análisis de las prácticas, no logró advertir que era una medida instaurada por disposiciones legislativas. Por ello, al momento de conceptualizar las disciplinas, relegó a las leyes a un rol prohibitivo y secundario.

Siempre en el marco de la generalización de las disciplinas, en la clase del 16 de enero de 1974, Foucault postuló que la difusión del poder psiquiátrico se había alcanzando con motivo de la psiquiatrización del niño idiota o imbécil. Hacia 1840 la idiotez dejó de ser concebida como una forma de locura, pero se la institucionalizó en los manicomios, algo necesario para que padres y madres pudieran dedicarse a sus actividades laborales sin necesidad de cuidar de sus hijos e hijas. De todos modos, cabe preguntarse cómo, a la vez que se sustraía a la idiotez del ámbito de la locura, se mantuvo el encierro y se inició un proceso de medicalización. Esto puede responderse a partir de la ley de 1838, que disponía que el costo de la internación de los y las idiotas estuviera a cargo del distrito, siempre y cuando los médicos detectaran, además de la idiotez, alguna peligrosidad: "el peligro es el elemento que tercia para permitir la puesta 
en marcha del procedimiento de internación y asistencia" (Foucault, 2003: 217). Bajo este dispositivo, el idiota se transformó en anormal y peligroso, y esto permite explicar por qué durante el siglo XIX la categoría de anormalidad fue aplicada a los niños, pero no a los adultos. Pero además implicó que la psiquiatría ya no tuviese solamente como blanco la locura, sino que, inscribiéndose en una racionalidad disciplinaria, se convirtió en "el poder sobre lo anormal, el poder de definir quién es anormal, de controlarlo, de corregirlo" (Foucault, 2003: 219). La ley, no una norma emergente de una práctica microfísica, puso el funcionamiento el poder disciplinario sobre los niños idiotas, pero al conceptualizar las prácticas, Foucault no dudó en sostener que la peligrosidad, sanción y curabilidad, no estaban "ni en el derecho ni en la medicina. No son nociones jurídicas, ni psiquiátricas, ni médicas, sino disciplinarias" (Foucault, 2001t: 1540). En el plano descriptivo, mostró que la noción de peligrosidad se encontraba en la ley de 1838, pero al momento de inscribirla dentro de alguna tecnología de poder y trabajar en un plano más conceptual, olvidó esta descripción, la incluyó dentro de las disciplinas, y la separó de la legalidad. ${ }^{6}$ Dicho de otro modo, falló al momento de ajustar las conceptualizaciones a las prácticas abordadas.

Podría sostenerse que el encierro a partir de las lettresde-cachet, el control de los obreros con la instauración legal de la cartilla, y la inclusión de la noción de peligrosidad en la ley, no muestran la existencia de un derecho disciplinario porque nada dicen sobre el control del tiempo, el espacio, y las actividades de los individuos. Frente a esta posible objeción, hay que aclarar que fue el propio Foucault quien ubicó estos dispositivos en el marco del funcionamiento de las disciplinas, pero en sus descripciones falló al advertir que se trataban de

6 Foucault mostraba que la justicia penal castigaba en función de la acción del delincuente, y de su eventual peligrosidad, algo que era "desorbitante en relación con ese derecho penal [...] que debía sancionar, de forma absolutamente igualitaria, las infracciones definidas explícitamente y previamente por la ley" (2001u: 463). 
dispositivos legales, o a pesar de advertirlo, en el plano conceptual no incluyó a las leyes en la órbita del poder disciplinario. Asimismo, en mayor o menor medida, las lettres-de-cachet y la cartilla, entiendo que delinean dispositivos de control disciplinario. De todas maneras, creo existe un mejor ejemplo para mostrar cómo ley ha operado como un mecanismo de control del tiempo y de las actividades de los individuos.

\section{VII.b. La ley disciplinaria}

Uno de los ejemplos que utilizó Foucault para dar cuenta del control de la temporalidad individual fue la reorganización de la Escuela de los Gobelinos en 1737, que implementó una detallada disciplina en la utilización del tiempo: excepto sábado y domingo se instituían dos horas diarias de trabajo; se controlaba la asistencia; se dispuso la división en tres clases de acuerdo al nivel de conocimiento; los alumnos tenían que realizar deberes individuales de modo periódico, y a fin de cada año se medían sus progresos. La reforma debe inscribirse en el desarrollo una novedosa técnica de poder

para tomar a su cargo el tiempo de las existencias singulares; para regir las relaciones del tiempo, de los cuerpos y de las fuerzas; para asegurar una acumulación de la duración; y para invertir en provecho o en utilidad siempre creciente el movimiento del tiempo (Foucault, 1975: 158).

La Manufactura de los Gobelinos -Manufactura Real de Muebles de la Corona- fue instituida en 1664 por Jean-Babtiste Colbert, Ministro de la Corte de Luis XIV. Sus reglas de organización se estipulaban a través de disposiciones legales -edictos y Resoluciones (Arrêt) del Consejo de Estado del Rey-. Siguiendo la fuente utilizada por Foucault en sus investigaciones -Le Manufacture nationale des Gobelins de Edóuard Gerspach-, se advierte que toda la administración, y hasta la creación de la Manufactura se realizó por edictos reales. Es más, el libro de Gerspach se inicia con la exposición de motivos del Edicto del Rey para el establecimiento de una Manufactura de Muebles 
en los Gobelinos (Gerspach, 1892: 1). Las disposiciones legales no solamente crearon la Manufactura, sino que la reorganización de 1737, que para Foucault se erige como una muestra del control sobre el tiempo y los cuerpos que imprime el poder disciplinario, fue dispuesta por una Resolución del Consejo de Estado del Rey del 16 de abril de 1737 (Gerspach, 1892: 263). Este caso paradigmático del poder disciplinario representa, también, un caso paradigmático de una ley no represiva ni vinculada con la matriz liberal, sino funcionando bajo una racionalidad estrictamente disciplinaria.

\section{Notas finales}

Foucault se preocupó por marcar las discontinuidades en las epistemes, las reglas de producción de los discursos, las relaciones de poder, el gobierno de sí y de los otros. Notar esas discontinuidades, en especial en el plano de las relaciones de poder, fue posible gracias a una detallada y fina atención a las prácticas. A partir de una focalización en las prácticas, Foucault entendió que la teoría jurídico política de la soberanía y la representación jurídica del poder no eran marcos teóricos precisos para estudiar las relaciones de poder, y entonces delineó una nueva analítica mucho más ajustada a esas prácticas. A primera vista, Foucault se presenta como un delicado observador de las prácticas, y de ellas extrae las conceptualizaciones para dar cuenta de ellas y analizarlas.

Toda la prolijidad, precisión y agudeza en la atención a las prácticas, y la reconstrucción conceptual a partir de ellas, comienza a desdibujarse cuando tomamos como dominio el modo en que Foucault tematizó el derecho. En un plano conceptual, aludió al derecho en términos de herramienta de prohibición, y al mismo tiempo, como derechos liberales, quedando en un segundo plano en las tecnologías y dispositivos que permitían el ejercicio de poder. Sin embargo, creo que esta dimensión conceptual adolece de un grave desajuste respecto de las prácticas a las que se refiere: en algunos casos por no 
describir prolijamente las prácticas, y en otros por no delinear de modo preciso los conceptos que se correspondían con ellas, Foucault no logró dar cuenta del modo en que el derecho puede funcionar como una herramienta para hacer efectivo el accionar de las disciplinas. Ese ojo agudo que logró advertir las discontinuidades en las relaciones de poder, que se esforzó en extraer sus conceptos de las propias prácticas disciplinarias, quedó enceguecido al momento de realizar una conceptualización del derecho que estuviera ajustada a esas mismas prácticas.

Marcadas estas deficiencias, quienes estamos preocupados por el modo en que el derecho se inscribe y se articula con prácticas de poder, no debemos desechar la obra de Michel Foucault. Más bien, de lo que se trata, es de situar al derecho dentro de la analítica del poder, pero, en este caso, no con Foucault, sino a pesar de Foucault.

\section{Referencias}

Beck, A, (1996). Foucault and Law: The Collapse of Law's Empire. Oxford Journal of Legal Studies 16, 3, 489-502.

Castro Orellana, R. (2004). Ética para un rostro de arena. Michel Foucault y el cuidado de la libertad. Madrid: Universidad Complutense de Madrid.

Ewald, F. (1986a). The Law of Law. En G. Teubner (Ed.), Autopoietic Law: A New Approach to Law and Society (36-50). New York and Berlin: De Gruyer.

(1986b) A concept of social law. En G. Teubner (Ed.), Dilemmas of Law in the Welfare State (40-75). New York and Berlin: De Gruyer.

(1986c). L`Etat providence. Paris: Bernard Grasset.

Foucault, M. (1975). Surveiller et punir. Paris: Gallimard.

(1976). Histoire de la sexualité I. La volonté de savoir. Paris: Gallimard.

(1984). L'ordre du discours. Paris: Gallimard.

(1999). Les anormaux. Cours au Collège de France (1974-1975).

Paris: Gallimard. 
(2001a). Les anormaux. En Dits et écrits I (1690-1696). Paris: Gallimard.

(2001b). La société punitive. En Dits et écrits I (1324-1338). Paris: Gallimard.

(2001c). L'asile illimité. Dits et écrits II (271-275). Paris: Gallimard. (2001d). Crise de la médicine o crise de la antimédicine? Dits et écrits II (40-58). Paris: Gallimard.

(2001e). Sur la sellette. Dits et écrits I (1588-1593). Paris: Gallimard. (2001f). Préface. Dits et écrits I (1063-1065). Paris: Gallimard.

(2001g). La folie, l'absence d'œuvre. Dits et écrits I (440-448). Paris: Gallimard.

(2001h). Folie, littérature, société. Dits et écrits I (972-996). Paris: Gallimard.

(2001i). De la nature humaine: justice contre-pouvoir (1339-1380). Dits et écrits I. Paris: Gallimard.

(2001j). Enquête sur les prisons: brisons les barreaux du silence. Dits et écrits I (1044-1050). Paris: Gallimard.

(2001k). Je perçois l'intolérable. Dits et écrits I (1071-1073). Paris: Gallimard.

(20011). Prisons et révoltes dans les prisons. Dits et écrits I (12931300). Paris: Gallimard.

(2001m). En guise de conclusion. Dits et écrits I (1284-1287). Paris: Gallimard.

(2001n). Le pouvoir, une bête magnifique. Dits et écrits II (368382). Paris: Gallimard.

(2001o). Entretien avec Michel Foucault. Dits et écrits II (140-160). Paris: Gallimard.

(2001p). Sexualité et pouvoir. Dits et écrits II (552-570). Paris: Gallimard

Les rapports de pouvoir passent à l'intérieur des corps (entretien avec L. Finas). Dits et écrits II. Paris: Gallimard.

(2001q). Les mailles du pouvoir. Dits et écrits II (1001-1020). Paris: Gallimard

(2001r). Le jeu de Michel Foucault. Dits et Écrits II (298-329). Paris: Gallimard. 
(2001s). La vérité et les formes juridiques. Dits et écrits I (14061514). Paris: Gallimard.

(2001t). Table ronde sur l'expertise psychiatrique. Dits et écrits I (1532-1534). Paris: Gallimard.

(2001u). L'évolution de la notion d' "individu dangereux" dans la psychiatrie légale du XIX siècle. Dits et écrits II (443-464). Paris: Gallimard.

(2003). Le pouvoir psychiatrique. Cours au Collège de France (1973-1974). Paris: Gallimard.

Gerspach, E. (1892). Le Manufacture Nationale des Gobelins. Paris: Librairie Ch. Delagrave.

Golder, B., Fitzpatrick, P. (2009). Foucault's Law. London: Routledge.

Hirst, P. (1986). Law, Socialism and Democracy. London: Allen \& Unwin.

Hunt, A. (1992a). Foucault's Expulsion of Law. Law and Social Inquiry, 17, 1, 1-38.

(1992b). Law and the Condensation of Power. Law and Social Inquiry, 17, 1, 57-62.

Kennedy, D. (1991). The Stakes of Law, or Hale and Foucault! Legal Studies Forum 25, 4, 327-366.

Le Crom, J.-P. (2003). Le livret ouvrier au XIXe siècle entre assujettissement et reconnaissance de soi. En D. Gaurier, P.-Y. Legal, Y. Le Gall (Dirs.), Du droit du travail au droits de l'bumanité (91-100). Rennes: Presses Universitaires de Rennes.

Pinel, P. (1801). Traité médico-philosophique sur l'aliénation mentale, ou la manie. Paris: Richard, Caille et Ravier Libraires.

Rose, R., Valverde, M. (1998). Governed by Law? Social and Legal Studies 7, 4, 541-551.

Tadros, V. (1998). Between Governance and Discipline: The Law and Michel Foucault. Oxford Journal of Legal Studies 18, 1, 75-103.

Wickham, G. (2002). Foucault and Law. En R. Banakr, M. Travers (Eds.), An Introduction to Law and Society Theory (217-232). Oxford: Hart.

(2006). Foucault, Law and Power: A Reassessment. Journal of Law and Society, 33, 4, 596-614. 